\title{
Photostabilization of Polystyrene Films by Chromium complex
}

\author{
Burak.Kadhim $^{1 *}$ Ahamed Ahamed $^{2}$ Amir Fadhil Dawood ${ }^{1}$ Karim H. Hassan ${ }^{1}$ \\ ${ }^{1}$ Department of Chemistry, College of Science, University of Diyala, Baquba, Diyala, Iraq. \\ ${ }^{2}$ Department of Chemistry, College of Science, University of Mustansiriyah, Bagdad, Iraq.
}

\section{Abstract}

The photo sensitized degradation of polymer system is occasionally used as a means of solving the problem of environmental pollution, photostabilization of polystyrene films using chrom complexes was investigated. Poly styrene films with a thickness of $80 \mu \mathrm{m}$ and contains complexes concentration of $0.05 \% \mathrm{wt}$ were produced by the casting method with chloroform being the solvent The photostabilization activities of these complexes were determined by monitoring changes in carbonyl, $\left(\mathrm{I}_{\mathrm{CO}}\right)$ and hydroxyl, $\left(\mathrm{I}_{\mathrm{OH}}\right)$ indices and calculating the photodecomposition rate constant $\left(\mathrm{k}_{\mathrm{d}}\right)$, the average molecular weight for the studied films The results obtained showed that the photostabilization activity of polystyrene film in the presence of the complexes as additive follows the trends:

$\mathrm{Cr}\left[\mathrm{S} 2 \mathrm{CN}\left(\mathrm{C}_{2} \mathrm{H}_{5}\right)_{2}\right]_{3}<\mathrm{Cr}\left[\mathrm{C}_{6} \mathrm{H}_{4} \mathrm{NO}_{2}\right]_{3}<\mathrm{PS}<\mathrm{Cr}(\mathrm{acac})_{3}$

Keywords: Photostabilization ; Polystyrene; Chromium complexs; Environment.

\section{Introduction}

Many polymeric materials exposure to ultraviolet (UV) radiation cause a significant degradation as it causes photooxidative degradation which results in breaking of the polymer chains, produces free radical and reduces the molecular weight, causing deterioration of mechanical properties and leading to useless materials, after an unpredictable time

Polystyrene (PS) which is one of the most important material in the modern plastic industry, has been used all over the world, due to its excellent physical properties and low-cost. When polystyrene is subjected to UV irradiation in the presence of air, it undergoes a rapid yellowing and a gradual embrittlement. The mechanism of PS photolysis in the solid state (film) depends on the mobility of free radicals in the polymer matrix and their bimolecular recombination. 
The UV-photodegradation of PS films has been studied using fluorescence spectroscopy, excitation and dispersed fluorescence spectra were also collected to monitor the chemical changes in the films. These fluorescence gave direct evidence that degradation products indicated to conjugated double bond along the polystyrene backbone named polyene structures- $(\mathrm{C}(\mathrm{C} 6 \mathrm{H} 5)=\mathrm{CH})$ n. Polyene structure is responsible for color change of PS under UV-exposure].

It is well known that the photo sensitized degradation of polymer system is occasionally used as a means of solving the problem of environmental pollution by plastic litter. The attempts to develop plastics with reduced outdoor stability are based on the syntheses of polymers with light-sensitive groups such as aliphatic ketone groups located predominantly in the main chain or independent (side) groups (Emad Yousif and Raghad Haddad,2013 ; Khalid E. Al Ani and,2015) and also the modification of polymers by the addition of another polymer (H.Omicihi,M.Hagiwara and K.Araki,1979;H.Omicihi,M.Hagiwara,1981) to do so in addition of using or application of photosensitizes which are added to the polymers or the plastic to photosensitize them against degradation process (AL-Niaimi, A. F. D el at ,2018).

A number of research papers have appeared in literature dealing with the photosensitized degradation of polymers by addition of transition-metals salts and complexes (J.F.Rabek .1994; Hameed. K. ALI and Abdulhameed. H. SHUKKUR ,2014). Preliminary it is found that the photodegradation of the polystyrene film was affected by the type of metal, concentration of the complex in addition to the kind of ligand and film thickness (Hameed. K. ALI and Abdulhameed. H. SHUKKUR ,2014; A.F. Dawood.ALNiaimi2006). It was reported also that the photo-stability of PS was reduced by the addition of bromine containing flame retardant, and appeared to depend upon the chemical structure of the polymeric additives (A.F. Dawood.AL-Niaimi,2002). For PS containing carbonyl group, it was found that the photodegradation increased with increasing in irradiation time. The changes in the average molecular weight in photooxidized PS were produced as consequences of chain dissociation by Norrish Type II reaction

\section{Materials and methods}

\subsection{A Materials used}

The organic chemicals used are Polystyrene, Petroleum ether, Picolinic acide, ethanol, Benzene, Urea, sodium diethyl dithiocarbamat whereas the inorganic one are chromium 
chloride, $\mathrm{CrCl}_{3} \cdot 6 \mathrm{H} 2 \mathrm{O}$. All these starting materials as well solvents were purchased commercially and used without any further purification except the polystyrene which was re-precipitated from chloroform solution with alcohol several times and finally dried under vacuum at room temperature for 24 hours.

\subsection{B Instruments used}

Accelerated weathering Q.U.V tester (Q-panal company,USA), was used for irradiation of polystyrene films at light intensity flux of $1.8 \times 10^{-8}$ Einstein $\mathrm{dm}^{-3} \mathrm{sec}^{-1}$ determined by potassium ferri-oxalate actinometrical technique( G.Ganqlize and S.Hubiq ,1989). Infrared spectrophotometer 4200-JASCO was used for monitoring the growth of carbonyl and hydroxyl groups at $\left(1730,3440 \mathrm{~cm}^{-1}\right)$ respectively whereas the ultravioletvisible spectrophotometer type V-650-JACSO was used to measure the changes in the UV-visible spectrum during irradiation at a wavelength of maximum absorption $\left(\lambda_{\max }\right)$. Film thickness was measured by a micrometer type 2610 a, Germany.

\subsection{Synthesis of complexes}

1- Triple (Estelle Asito Neto) Chrome $\operatorname{Cr}\left(\mathrm{C}_{5} \mathrm{H}_{7} \mathrm{O}_{2}\right)_{3}$; This complex is attended by the way the world is used (Fernelius and blanch) by adding $2.66 \mathrm{~g}(0.01)$ of chromium chloride crystallized to (100) $\mathrm{ml}$ of distilled water and after dissolving, add (20) grams of urea. $6 \mathrm{~g}$ (0.06) Mol of acetyl acetone covers the reaction blend in an hour bottle and heated on a steam bath for 12 hours. When urea is dissolved, ammonia is released. Dark red crystals (deep maroom), which are filtered and dried with air at room temperature, then dissolve the dried raw compound in (20) gasoline is hot and added (75) $\mathrm{ml}$ of hot pure ether slowly and cools to laboratory temperature, and takes its spectrumI R and UV ( Buraq Nadhim Kadhim,2018) .

2- Triple (Diethyl Thiayo carbamtu) chromium $\mathbf{C r}\left[\mathbf{S}_{2} \mathbf{C N}\left(\mathbf{C}_{2} \mathbf{H}_{5}\right)_{2}\right]_{3}$ :This complexity is prepared by the way suggested by Whitre \&co. Workers by mixing of a water solution for $(1,35 \mathrm{mg})(0.005) \mathrm{mol}$ of hexagonal chromium chloride with a water solution of ligand salt $\mathrm{Na}\left[\mathrm{S}_{2} \mathrm{CN}\left(\mathrm{C}_{2} \mathrm{H}_{5}\right)_{2}\right](2.57 \mathrm{mg})(0.015)$ mol with stirring, which consists of a direct deposition of a color (bluish violet) washed with distilled water and dried under pressure and the temperature of the laboratory. The IR and UV spectra are given in the appendix and have a complex melting point $\left(243^{\circ} \mathrm{c}\right)$. ( Buraq Nadhim Kadhim,2018).

3- Tri(piclinate) chromium $\mathbf{C r}\left[\mathbf{C}_{6} \mathbf{H}_{4} \mathbf{N O}_{2}\right]_{3}$ :This complexity is attended by following the method suggested by RAY\&co.workers by dissolving (1.8 mg) (0.005) Mole of $\mathrm{Cr}$ (acac) 3 in $60 \mathrm{ml}$ of ethanol the range is mixed with a( $0.62 \mathrm{mg})(0.005)$ Mole of 
pycloonic acid in $25 \mathrm{ml}$ of the same solvent where the color crystals are separated (Maronite). Collect and wash and ethanol Dry and I'm in a dry place. It took a spectrum of IR and UV and a complex melting point (216 c c $^{\circ}$. ( Buraq Nadhim Kadhim,2018)

\subsection{Film preparation}

Polystyrene and metal complexes were dissolved in $\mathrm{CHCI}_{3}$ to form polystyrene films which contain $0.05 \%$ wt of additive and have $(80 \mu \mathrm{m})$ thickness. The films were prepared by evaporation technique at room temperature for 24 hours in order to remove the possible residual may present.

\subsection{E Irradiation experiments}

The films were located $(6 \mathrm{~cm})$ a part from the UV lamps sources [four fluorescent lamps with 40 watt power)]. These lamps are of the type UV-B 313, giving a spectrum range between 290-360 $\mathrm{nm}$ with a maximum being at wavelength $313 \mathrm{~nm}$. The irradiated samples were rotated from time to time to ensure that the intensity of light incident on all samples was the same.

\subsection{F Spectrophotometric measurements}

For Infrared spectrophotometer and in order to eliminate the effect of sample thickness we adopted the band indexing method (D.Cmellar ,A.B.Mair and G.S.Scott,1973) .A band index, $I_{s}$ is defined as $I_{s}=A_{s} / A_{r}$, where $A_{s}$ is the absorbance of the studied band and $A_{r}$, the absorbance of the reference band at $1450 \mathrm{~cm}^{-1}$ which is the bending mode of - $\mathrm{CH}$ - group in polystyrene( Buraq Nadhim Kadhim,2018).Actual absorbance ,the difference between the absorbance of top peak and the base line one $\left(\mathrm{A}_{\text {Top peak }}-\mathrm{A}_{\text {Base line }}\right)$, is calculated using the base line method (A.F. Dawood.AL-Niaimi,1999). The ultraviolet-visible spectrum was measured during irradiation time for each compound at a wavelength of maximum absorption band $\left(\lambda_{\max }\right)$ for calculating the rate photodecomposition constant $\left(\mathrm{k}_{\mathrm{d}}\right)$.

\subsection{G Measuring the photodegradation rate of polymer films using Ultraviolet- visible spectrophotometer}

Ultraviolet-visible spectrophotometry technique (Esraa Ismeal Al-Kjateb et .al,2016) was used to measure the changes in the UV-Visible spectrum during different irradiation times for a polymer film at a wavelength $\left(\lambda_{\max }=200-400 \mathrm{~nm}\right)$. The photodegradation rate constant for the Photostabilizer $\left(\mathrm{k}_{\mathrm{d}}\right)$ was calculated using the first order kinetic equation: 


$$
\ln (\mathrm{a}-\mathrm{x})=\ln \mathrm{a}-\mathrm{k}_{\mathrm{d}} \mathrm{t}
$$

where:

$\mathrm{a}$ is the additive concentration before irradiation, $\mathrm{x}$ is the additive concentration after irradiation time $\mathrm{t}$ which is in second.

If $\mathrm{A}_{\mathrm{o}}$ represents the absorption intensity of the polymer film containing additive before irradiation, $A_{\infty}$ is the intensity at infinite irradiation time and $A_{t}$ is the absorption intensity after irradiation time $\mathrm{t}$, then :

$\mathrm{a}=\mathrm{A}_{\mathrm{o}}-\mathrm{A}_{\infty}$ and $\mathrm{x}=\mathrm{A}_{\mathrm{o}}-\mathrm{A}_{\mathrm{t}}$

$a-x=A_{o}-A_{\infty}-A_{o}+A_{t}=A_{t}-A_{\infty}$

Substitution of (a) and (a-x) from equation (2) to equation (1) gives:

$\ln \left(\mathrm{A}_{\mathrm{t}}-\mathrm{A}_{\infty}\right)=\ln \left(\mathrm{A}_{\mathrm{o}}-\mathrm{A}_{\mathrm{t}}\right)-\mathrm{k}_{\mathrm{d}} \mathrm{t}$

Thus the plot of $\ln \left(\mathrm{A}_{\mathrm{t}}-\mathrm{A}_{\infty}\right)$ versus irradiation time (t) gives straight line with a slope equal to $\left(\mathrm{k}_{\mathrm{d}}\right)$. This indicates that the photodecomposition of the polymer is of first order.

\section{Results and discussion}

The chrom complexes were used as additive for photostabilization of polystyrene films. During UV irradiation polystyrene films intensity of absorption spectrum increased, the initial rates of increase in absorbance are relatively rapid at the begining ,however they gradually decline as the film becomes insoluble (crosslinked) and being slightly yellow in colored (due to formation of diene and triene structures) (J.F.Rabek, 1986; A.F. Dawood.AL-Niaimi,1999). The irradiation of polystyrene films led to change in the infrared spectra ,the growth in absorption bands at 3440 and $1730 \mathrm{~cm}^{-1}$ which are belong to hydroxyl and carbonyl groups respectively (A.F. Dawood.ALNiaimi,2006), from these absorptions , the carbonyl index $\left(\mathrm{I}_{\mathrm{CO}}\right)$ and hydroxyl index $\left(\mathrm{I}_{\mathrm{OH}}\right)$ were calculated with irradiation time. The effectiveness of these complexes on the rate of photodegradation of polystyrene films was monitored by following the $\left(\mathrm{I}_{\mathrm{CO}}\right)$ and $\left(\mathrm{I}_{\mathrm{OH}}\right)$ with irradiation time. In figures 2,3 and 4 , the $\left(\mathrm{I}_{\mathrm{CO}}\right)$ and $\left(\mathrm{I}_{\mathrm{OH}}\right)$ of complexes shows a lower growth with irradiation time with respect to polystyrene control film without additives. Since the growth of carbonyl and hydroxyl indexes with irradiation time are lower than that of the control, it is safe to conclude that these additives might be considered as photostabilizers of the polymer. An efficient photostabilizer shows a 
longer induction period. Therefore, the $\mathrm{Cr}\left[\mathrm{S} 2 \mathrm{CN}\left(\mathrm{C}_{2} \mathrm{H}_{5}\right)_{2}\right]_{3}$ is the most active photostabilizer ,followed by $\mathrm{Cr}\left[\mathrm{C}_{6} \mathrm{H}_{4} \mathrm{NO}_{2}\right]_{3}$, PS and finally the $\mathrm{Cr}(\mathrm{acac})_{3}$ which seem to be the least active one.

The change of $\ln \left(\mathrm{A}_{\mathrm{t}^{-}} \mathrm{A}_{\infty}\right)$ versus irradiation time, $\mathrm{t}$ for $\mathrm{Cr}\left[\mathrm{S} 2 \mathrm{CN}\left(\mathrm{C}_{2} \mathrm{H}_{5}\right)_{2}\right]_{3}$ additive in polymer as example is a straight line and is shown in (fig 2). This indicates that the rate is first order for the decomposition of polymer, the slope is equal to the value $\left(-\mathrm{k}_{\mathrm{d}}\right)$. The values of the all first order constants of all additives used calculated by the same way are shown in table 1.

The photostabilizers always possess low $\mathrm{k}_{\mathrm{d}}$ values, which mean that theses modified polymer films are stable towards UV light more than polystyrene without additive. Absorption in polystyrene film at 241,260 and $305 \mathrm{~nm}$ have been attributed to acetophenone, dicarbonyl structures and benzal acetophenone respectively (H.C.Beachell and L.H.Smiley,1967).

Of the results obtained, the efficiency of the organic compounds used as polystyrene stabilizers except $\mathrm{Cr}$ (acac) ${ }_{3}$ acts as a photocatalyst that can be arranged according to the change in the decomposition calculation, the molecular weight ratio(fig 5), Chain cutting(fig 6), decomposition grade(fig 7), polymerization grade(fig 2), inverse polymerization grade and quantum product for chain cutting as described in all previous forms.

\section{Conclusion}

Some of the additives used in this work have behaved successfully as photostabilizers for polystyrene chips

It is found that carbonyl and hydroxyl, $\mathbf{I}_{\mathbf{C O}}, \mathbf{I}_{\mathbf{O H}}$ at a thickness film of $80 \mu \mathrm{m}$, additive concentration, $0.05 \% \mathrm{wt} \%$ increased with time exposed to radiation and this rate of dissociation depends on type of additives used where $\mathrm{Cr}(\mathrm{acac})_{3}$ seem to be initiator while the other seem to be a photo stabilizer and follow :

$\mathrm{Cr}\left[\mathrm{S}_{2} \mathrm{CN}\left(\mathrm{C}_{2} \mathrm{H}_{5}\right)_{2}\right]_{3}<\mathrm{Cr}\left[\left(\mathrm{C}_{6} \mathrm{H}_{4}\right) \mathrm{No}_{2}\right]_{3}<\mathrm{PS}<\mathrm{Cr}(\mathrm{acac})_{3}$

Finally degree of polymerization, degree of dissociation, quantum yield value for cutting of polymer chain investigation indicated that all additives behaves as photo stabilizer except $\mathrm{Cr}(\mathrm{acac})_{3}$ which show otherwise and act as a photo initiator. 


\section{References}

-Yousif, E., \& Haddad, R. (2013). Photodegradation and photostabilization of polymers, especially polystyrene. SpringerPlus, 2(1), 398.

-Al Ani, K. E., \& Ramadhan, A. E. (2015). Kinetic Study of the Effect of Plasticization on Photodegradation of Polystyrene Solid Films. Materials Sciences and Applications, 6(07), 617.

-H.Omicihi,M.Hagiwara and K.Araki , Materials Sciences and Applications, 180,1923, 1979.

-H.Omicihi,M.Hagiwara , Polym.Photochem, 15,1981

-AL-Niaimi, A. F. D., Ahmed, A., \& Aliwy, S. B. (2018).Photodegradation Of Poly (Vinyl Chloride) Films With Some Cobalt (111) Complexes And Schiff Bases As Additives. International Journal Of Research In Pharmacy And Chemistry -Hameed. K. ALI and Abdulhameed. H. SHUKKUR (2014), International Journal of Applied and Natural Science, 3, 3,123-134.

J.F.Rabek,polymer photodegradation Mechanisms and experimental methods Stockholm ,1994.

A.F. Dawood.AL-Niaimi ,Diyala Journal for Applied Researches , 2, 2, 2006

A.F. Dawood.AL-Niaimi, Journal of Diyala, 12, 2002.

G.Ganqlize and S.Hubiq, Chemical Actinometry ," pure and Appl. Chem .1989, 6, 187.

Buraq Nadhim Kadhim, (2018). photodegradation of polystyrene doped with some organometallic compounds, Master in Chemistry.

D.Cmellar ,A.B.Mair and G.S.Scott .Eur.Polym.J.1973.9,219.

Esraa Ismeal Al-Kjateb,Ahmed Ahmed and Khaiaf F Alsamarrai,2016,' 'Pharmaceutical

Compounds as Photostabilizers','Journal of Al-Nahrain University, Vol.19(3),September,34-38.

A.F. Dawood.AL-Niaimi.( 1999).Ph.D. Thesis, University of Mustansiria, College of Science.

J.F.Rabek and J.Sanertra ,Macromolecules ,1986.19.167.

H.C.Beachell and L.H.Smiley, J ournal Polym.Sci, 1967,5,1633. 


\section{Appendices}

Table 1: photodecomposition rate constant $\left(\mathrm{k}_{\mathrm{d}}\right)$ of polystyrene films of $(80 \mu \mathrm{m})$ thickness and containing $0.05 \%$ wt additives.

\begin{tabular}{|r|c|}
\hline $\mathbf{K}_{\mathbf{d}}\left(\mathbf{h}^{-1}\right)$ & Film used \\
\hline 0.0031 & Polystyrene $+\mathbf{C r}(\mathbf{a c a c})_{\mathbf{3}}$ \\
\hline 0.0024 & Polystyren $\left.+\mathrm{Cr}\left[\mathrm{C}_{6} \mathrm{H}_{4}\right) \mathrm{NO}_{2}\right]_{3}$ \\
\hline 0.0002 & Polystyrene+Cr$\left[\mathbf{S}_{\mathbf{2}} \mathbf{C N}\left(\mathbf{C}_{2} \mathbf{H}_{4}\right)_{\mathbf{2}}\right]_{\mathbf{3}}$ \\
\hline 0.0026 & Polystyrene \\
\hline
\end{tabular}

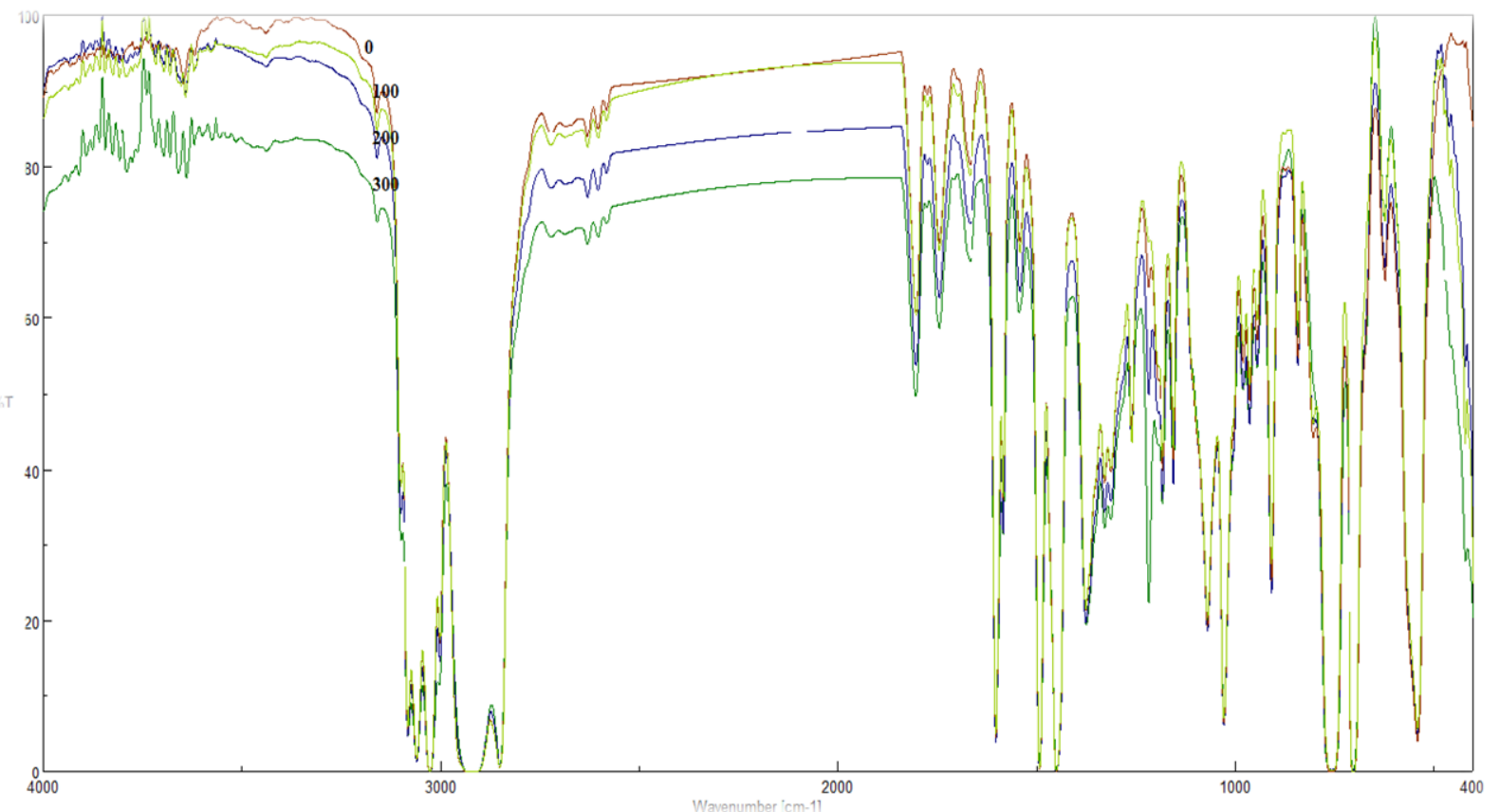

Figure 1:The IR of polystyrene chips with athicness of $80 \mu$ n before irradiation and after 300 hours. 


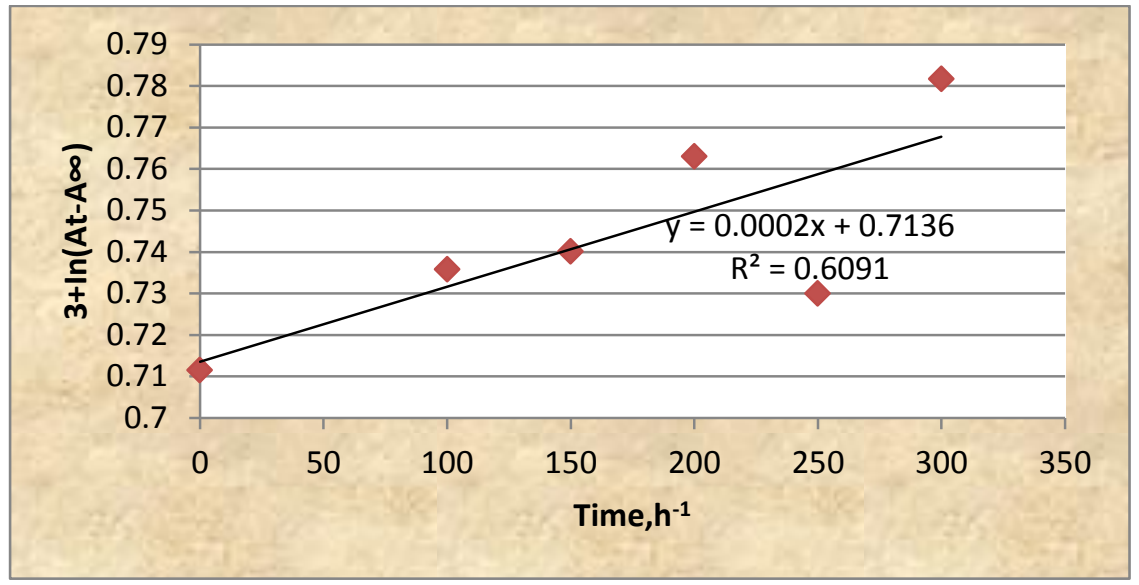

Figure2: Variation $\ln \left(\mathrm{A}_{\mathrm{t}}-\mathrm{A}_{\infty}\right)$ with time for polystyrene films of $(80 \mu \mathrm{m})$ thickness and containing $0.05 \%$ wt of $\mathrm{Cr}\left[\mathrm{S} 2 \mathrm{CN}\left(\mathrm{C}_{2} \mathrm{H}_{5}\right)_{2}\right]_{3}$ as additive.

Figure 3: Change of carbonyl index with irradiation time for polystyrene films, $80 \mu \mathrm{m}$ thickness and containing $0.05 \%$ wt of additives.

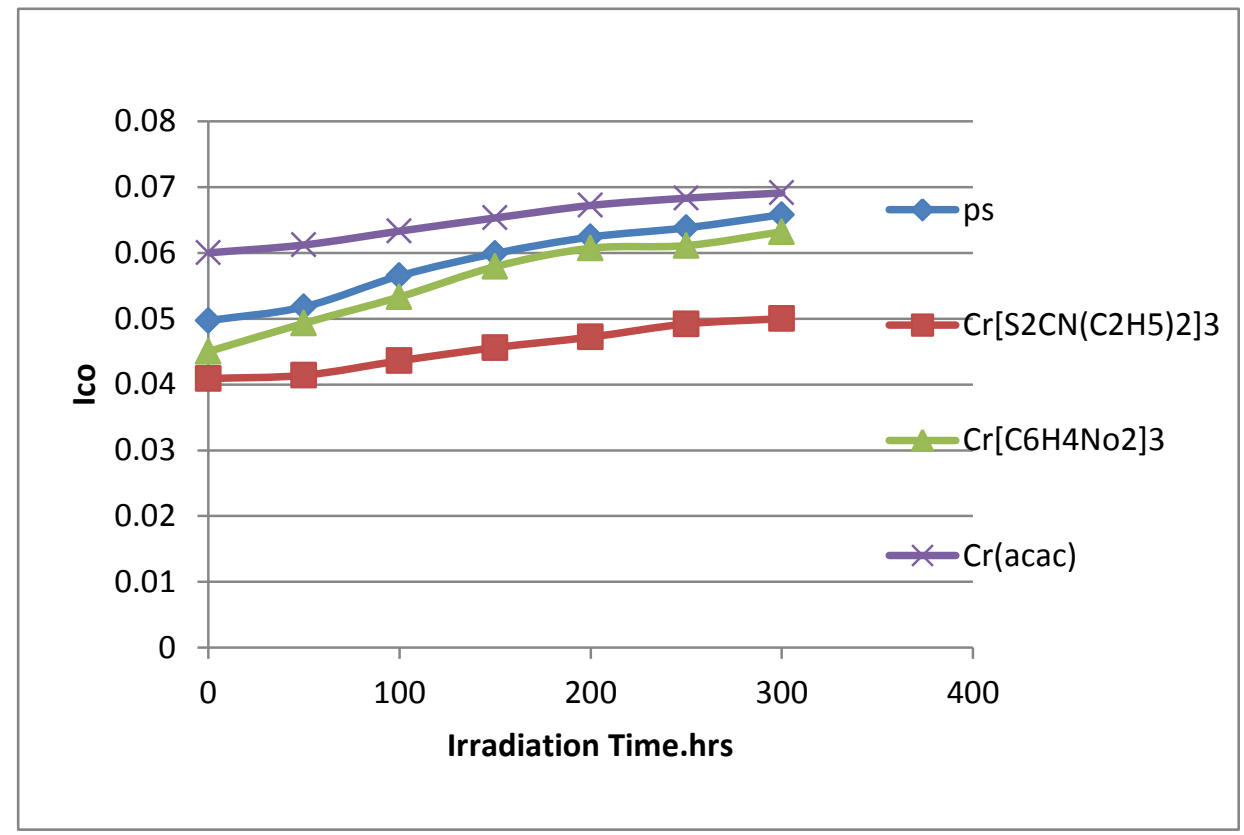


Figure 4: The relationship between the hydroxyl index and irradiation time for polystyrene films of $80 \mu \mathrm{m}$ thickness and those containing additives with a

concentration of $0.05 \%$ wt.
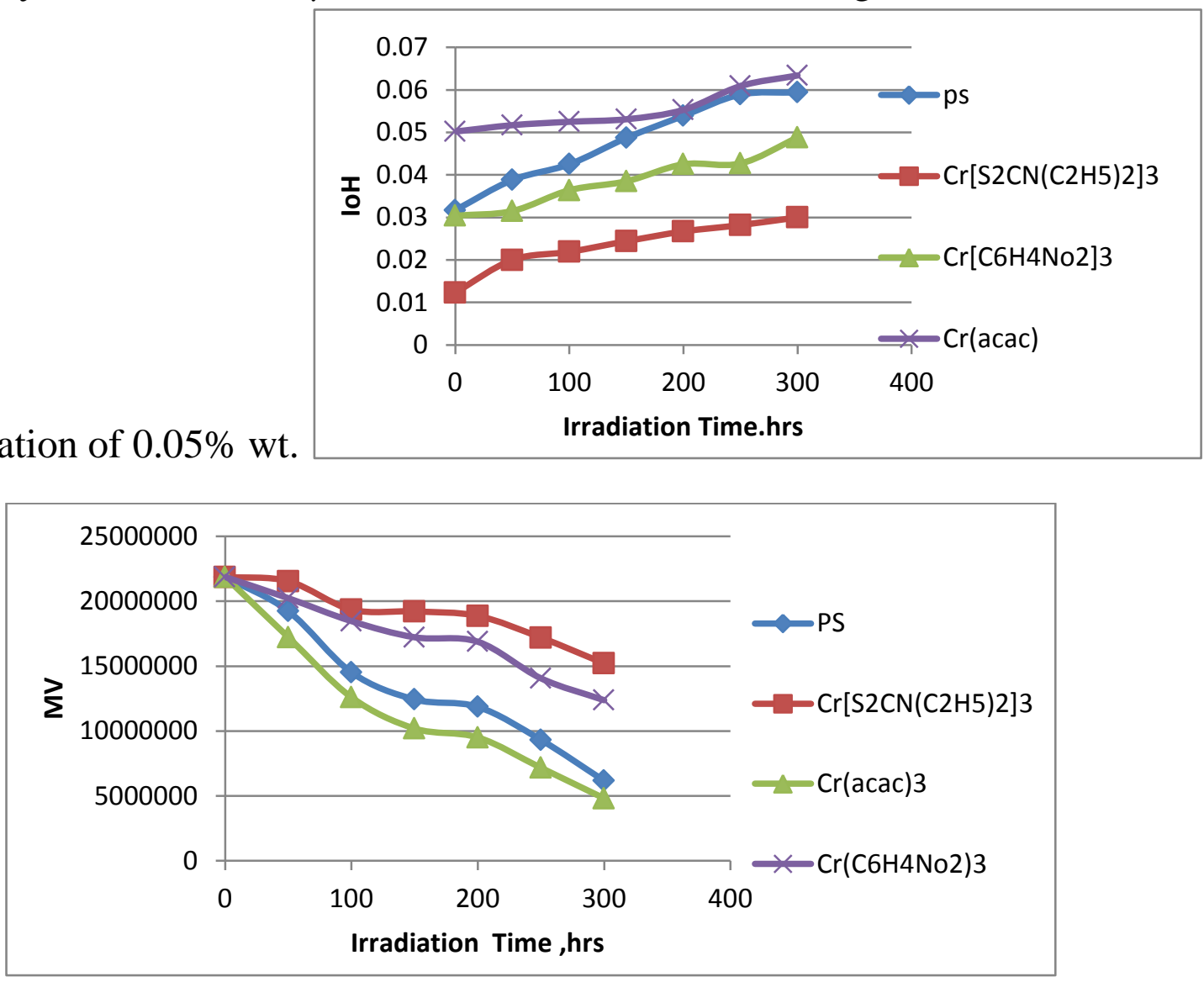

Figure5: Change ( v)and irradiation time for polystyrene films of $80 \mu \mathrm{m}$ thickness and those containing additives with a concentration of $0.05 \% \mathrm{wt}$.

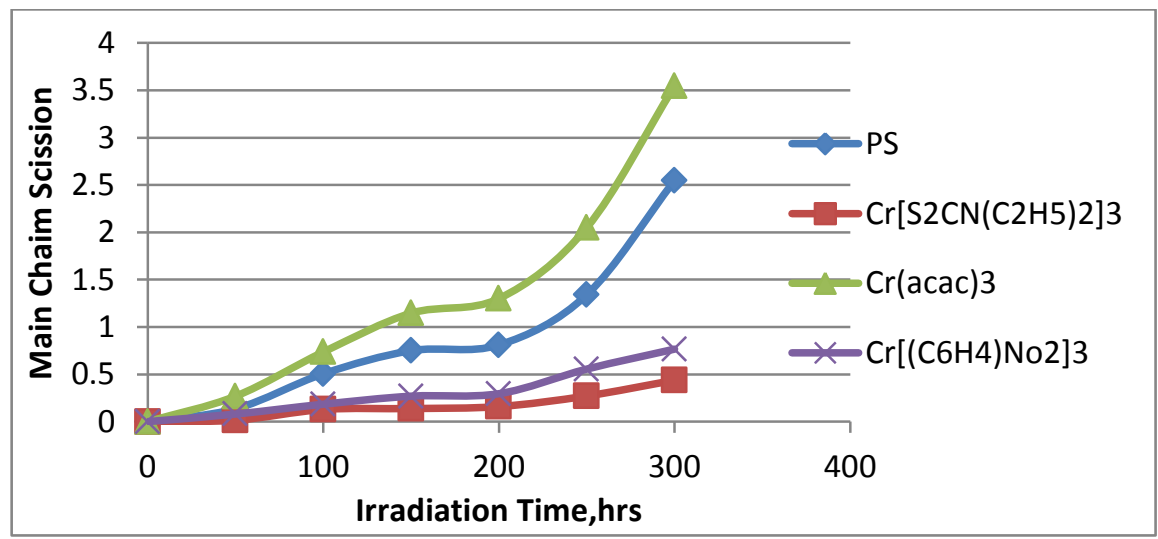

Figure6: Change (S)and irradiation time for polystyrene films of $80 \mu \mathrm{m}$ thickness and those containing additives with a concentration of $0.05 \% \mathrm{wt}$. 


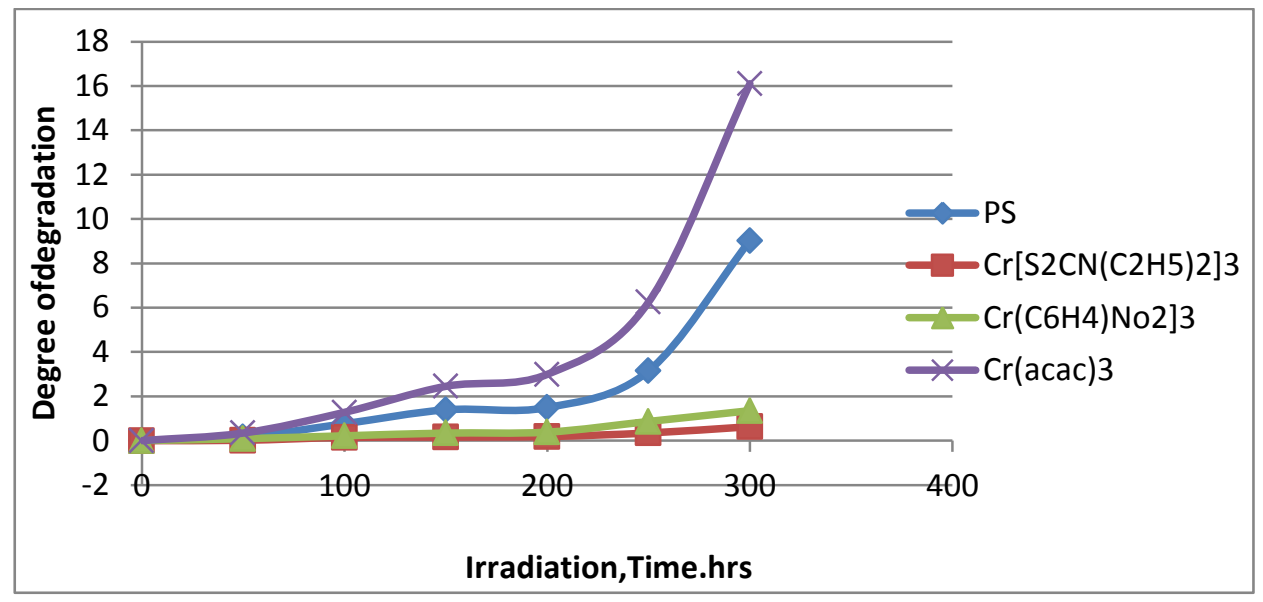

Figure7: Change (a)and irradiation time for polystyrene films of $80 \mu \mathrm{m}$ thickness and those containing additives with a concentration of $0.05 \% \mathrm{wt}$.

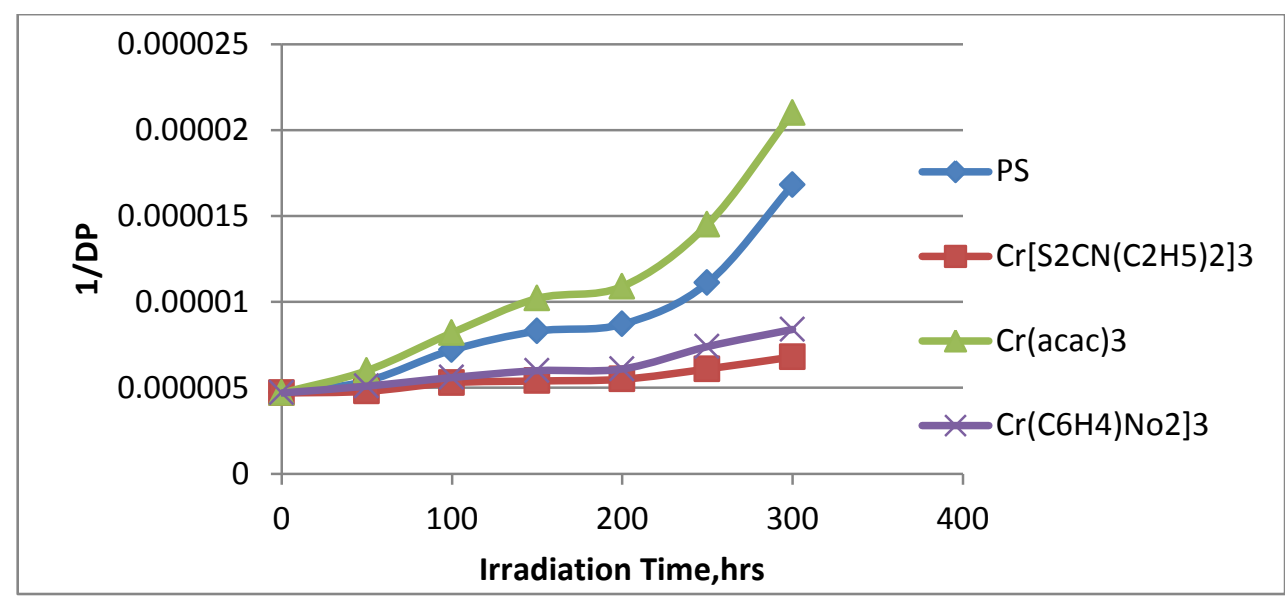

Figure8: Change (1\Dp)and irradiation time for polystyrene films of $80 \mu \mathrm{m}$ thickness and those containing additives with a concentration of $0.05 \% \mathrm{wt}$. 